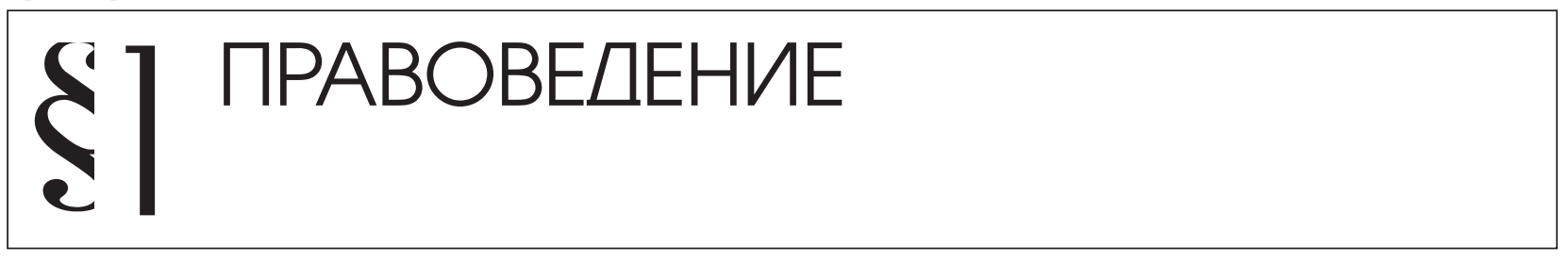

Паутова М.Н.

\title{
ПРАВОВОЙ РЕЖИМ ИНОСТРАННЫХ ИНВЕСТИЦИЙ В ТОПЛИВНО-ЭНЕРГЕТИЧЕСКОМ КОМПЛЕКСЕ РОССИЙСКОЙ ФЕДЕРАЦИИ
}

Аннотация: В статье рассматривается правовой режим иностранных инвестиций в топливно-энергетический комплекс Российской Федераџии. Рассматривается законодательство, а также судебная практика в отношении иностранных инвестиций в топливно-энергетический комплекс. Рассматриваются международно-правовые нормы, регулирующие инвестиции в ТЭК. Рассматривается вопрос о том, каким является наиболее выгодный для иностранных инвесторов правовой режим инвестирования, так вопрос о применимом режиме на практике приводит не всегда к однозначным результатам. Утверждается, что несмотря на установление национального режима в отношении иностранных инвестиций, топливно-энергетический комплекс по природе своей является той сферой хозяйственной деятельности, где в отступление от принципа (национальный режим) может применяться дискриминационный режим правового регулирования (режим наибольшего благоприятствования). В тоже время, отмечается, что на практике иностранные инвесторы 8 ТЭК поставлены в более выгодное положение, чем национальные, что связано с необходимостью привлечения иностранных инвестиций, а также технологий разведки и добычи энергоресурсов.

Ключевые слова: Правовой режим, топливно-энергетический комплекс, иностранные инвестиции, национальные инвестиции, национальный правовой режим, режим наибольшего благоприятствования, судебная практика, национальное право, международное право, прещедентное право.

Abstract: The article deals with the legal status of foreign investments in the fuel and energy complex of the Russian Federation. Author explored the legislation as well as judicial practice ruling over foreign investments in the fuel and energy complexof the Russian Federation. Special place is given to the international legal rules governing investments in the energy sector. It is alleged that, despite the establishment of national (non discriminatory) treatment of foreign investments, fuel and energy complex by its very nature is an area of economic activity, where by way of derogation from the principle of (national treatment) may be applied discriminatory legal regime (MFN status). At the same time, it is noted that, in practice, foreign investors in the energy sector put in a better position than nationals because of the need to attract foreign investment, as well as exploration and production technologies of energy.

Keywords: Legal regime, fuel and energy sector, foreign investment, national investment, the national legal regime, most favored nation treatment, litigation, domestic law, international law, case law.

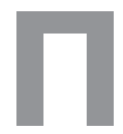

равовой режим иностранных инвестиций в топливно-энергетическом комплексе Российской Федерации, как и правовой режим практически любых отношений в современном праве, является комплексным, то есть регулируемым несколькими источниками - а в некоторых случаях даже и отраслями - права, а также сложным правовым явлением. Более того, такой характер правового режима иностранных инвестиций в топливно-энергетический комплекс (далее - ТЭК) Российской Федерации является ярко выраженным в связи с особенностями как самой отрасли энергетики, так и иностранным элементом данного объекта правового регулирования. Действительно, энергетика является той отраслью хозяйственных отношений, где вопросы безопасности имеют приоритетное значение и где, как следствие, правовое регулирование отношений отступает от классических диспозитивных методов гражданскоправового регулирования и содержит элементы публично-правового - в частности административноправового - регулирования. Более того, присутствие иностранного элемента ставит данный вопрос особо остро, так как иностранные инвестиции в ТЭК затрагивают вопросы энергетической безопасности государства и сохранения национального суверенитета. Следствием присутствия иностранного элемента в отношениях инвестирования в ТЭК, а также важности этой отрасли экономики, в отношении иностранного 
инвестора чаще всего применяется особый правовой режим, характеризующийся набором специальных норм и институтов, характерных для гражданского права. Таким образом, правовой режим иностранных инвестиций носит - как никакой другой правовой режим хозяйственных отношений - комплексный характер и отличается специфичностью применимых правовых норм и институтов.

В целом правовой режим иностранных инвестиций в российском правопорядке определяется ст. 4 Федерального закона от 9 июля 1999 г. № 160-Ф3 «Об иностранных инвестициях в Российской Федерации»[1]: «Правовой режим деятельности иностранных инвесторов и использования полученной от инвестиций прибыли не может быть менее благоприятным, чем правовой режим деятельности и использования полученной от инвестиций прибыли, предоставленный российским инвесторам...». Речь идет о том, что в теории инвестиционного права[2] называется национальным режимом иностранных инвестиций, который сегодня, в рамках глобализированной экономики, является наиболее распространённым режимом иностранных инвестиций, так как предоставляет не только зарубежным, но и отечественным инвесторам единые условия, гарантии и права, т.е. является не дискриминационным и, как следствие, привлекательным для иностранного инвестора, позволяя, таким образом, обеспечить приток иностранных инвестиций на национальные рынки государств, применяющих такие режимы иностранных инвестиций. Иначе говоря, на первый взгляд правовой режим иностранных инвестиций не является особенным, т.е. является единым для всех инвесторов (как национальных, так и зарубежных).

На начальном этапе становления инвестиционного права, в применении данного режима в топливноэнергетическом комплексе были заинтересованы сами инвесторы. Так, в частности, Ануфриева А.А. отмечает, что «... большинство экспортеров капитала заинтересованы в максимальном уравнивании их положения с положением национальных инвесторов, устранении препятствий при выходе на местные рынки и получении аналогичных с местными экономическими субъектами прав»[3]. В тоже время, в рамках глобализированной экономики, где между государствами наблюдается конкуренция за инвестора, «государствамимпортерам» инвестиций самим выгодно предоставить иностранному инвестору наиболее благоприятный - т.е. национальный режим инвестирования с целью привлечения иностранных инвесторов.

В тоже время, как мы отметили, ТЭК является особой отраслью хозяйственной деятельности, где к иностранным инвесторам, или их отдельным категориям из них, применяются особые правовые режимы, большая часть из которых характеризуется применением особых правовых норм и институтов.

На международно-правовом уровне не устанавливается обязательство создания для иностранных инвестиций в ТЭК наиболее благоприятного - т.е. национального режима инвестиций. Так, например, пп. 2 и 3 ст. 10 Договора к Энергетической хартии[4] гласит: «Каждая Договаривающаяся Сторона стремится предоставлять Инвесторам других Договаривающихся Сторон, в том, что касается Осуществления Инвестиций на ее Территории,... режим, не менее благоприятный, чем тот, который она предоставляет своим собственным Инвесторам или Инвесторам любой другой Договаривающейся Стороны или любого третьего государства, в зависимости от того, какой из них является наиболее благоприятным». Иначе говоря, в отличие от единого правового режима иностранных инвестиций, применяемого как к российским, так и зарубежным инвесторам в российском праве (ст. 4 Федерального закона от 9 июля 1999 г. № 160-Ф3 «Об иностранных инвестициях в Российской Федерации»), Договор к энергетической хартии не обязывает государства примен ять, так называемый, национальный режим к иностранным инвестициям в ТЭК. Более того, данный акт так и не был ратифицирован и, как следствие, не имеет обязательной силы в российском правопорядке[5].

В тоже время, уже упомянутая ст. 4 Федерального закона от 9 июля 1999 г. № 160-Ф3 «Об иностранных инвестициях в Российской Федерации» предусматривает ряд, так называемых, «изъятий ограничительного характера» из национального режима иностранных инвестиций, в частности, в целях «...обеспечения обороны страны и безопасности государства». Иначе говоря, в соответствии с позитивным правом применение национального режима к иностранным инвестициям может быть ограничено в данных целях, что чаще всего касается определённых секторов экономики. Остается лишь определить возможно ли изъятие из общего принципа национального режима иностранных инвестиций в отношении сферы энергетики, что данный закон прямо не указывает.

Об отнесении сферы энергетики - или по крайней мере отдельных видов деятельности в сфере энергетики - к одной из отраслей, затрагивающих вопросы безопасности государства и, как следствие, позволяющих осуществлять изъятия из принципа национального режима иностранных инвестиций, свидетельствует Федеральный закон «О порядке осуществления иностранных инвестиций в хозяйственные общества, 
имеющие стратегическое значение для обеспечения обороны страны и безопасности государства»[6], который относит сделки касающиеся «...геологического изучения недр и (или) разведки и добычи полезных ископаемых на участках недр федерального значения» (п. 3 ст. 2) именно к таким, к которым может применяться особый, т.е. менее благоприятный для иностранного инвестора, правовой режим.

Судебная практика идет именно по пути закрепления менее выгодного правового режима для иностранных инвестиций в отдельные сферы хозяйственной деятельности. Действительно, по устоявшейся практике к иностранным инвесторам применяется лишь, так называемый, режим наибольшего благоприятствования, а не национальный режим, т.е. режим позволяющий применять к иностранным инвесторам менее благоприятные условия инвестирования, чем к национальным, не устанавливая, в тоже время, дискриминационных условий инвестирования между категориями различных иностранных инвесторов. Президиум Высшего Арбитражного Суда Российской Федерации в информационном письме № 58 от 18 января 2001 г. “Обзор практики разрешения арбитражными судами споров, связанных с защитой иностранных инвесторов"[7] подтвердил, что дифференцированное регулирование арендных ставок на землю областным законодательством не противоречит требованиям Закона РСФСР «Об иностранных инвестициях в РСФСР»[8] (ст.6), предусмотревшим одинаковый правовой статус для иностранных и российских предпринимателей (национальный режим). Можно только сожалеть, что такая трактовка областного законодательства, устанавливающего в рамках рассмотренного дела дискриминационный размер арендной платы за землю в отношении иностранных юридических лиц, который был больше применимого в отношении национальных инвесторов, была признана не противоречащей российскому инвестиционному праву, предусматривающему применение в отношении иностранных инвесторов национального режима, так как такой подход делает инвестиции в российскую экономику менее привлекательными для иностранных инвесторов.

Судебная практика пошла дальше и однозначно подтвердила идею о том, что из ст. 4 Федерального закона от 9 июля 1999 г. № 160-Ф3 «Об иностранных инвестициях в Российской Федерации»[9], устанавливающей в отношении иностранного инвестора национальный режим, существует ряд исключений, адаптирующих правовые режимы иностранных инвестиций в отдельных сферах хозяйственной деятельности. Так, например Постановлением Президиума
Высшего Арбитражного Суда Российской Федерации от 15 мая 2002 г. № 9079/01 установлено, что «статья 4 этого Закона определяет общий режим деятельности иностранных фирм в России: «правовой режим деятельности иностранных инвесторов не может быть менее благоприятным, чем правовой режим деятельности, предоставленный российским инвесторам, за изъятиями, устанавливаемыми федеральными законами» (выделено автором). Иначе говоря, данное решение подтверждает идею о том, что в российском правопорядке установлен ряд ограничений на ведение хозяйственной деятельности иностранными инвесторами в отдельных отраслях экономики (в данном решении речь шла о международных автомобильных перевозках), к которым, в том числе, относится и инвестиционная деятельность иностранных инвесторов в ТЭК.

Стоит отметить, что изъятия из национального режима в отношении иностранных инвесторов ТЭК не являются изобретением российского правопорядка. По свидетельствам А.Г. Лисицына-Светланова «...вызывают сомнения заявления и доводы Европейского Союза, что Россия якобы идет по пути ограничения присутствия на своем энергетическом рынке иностранных инвесторов, в то время как аналогичный рынок стран Европейского Союза является, как утверждают их представители, открытым. Этот упрек в отношении России не выдерживает критики, а вот в странах Европейского Союза, несмотря на либерализацию европейского рынка электроэнергетики и газа, действует директива о добыче углеводородов, согласно которой сохраняется право государств-членов вводить ограничения в отношении лиц из третьих стран на определенные виды деятельности в энергетической сфере»[10]. Иначе говоря, практика введения ограничений на иностранные инвестиции в ТЭК является распространённой, что подтверждается, как мы уже отметили, и формулировками международного права; в частности, Договора к энергетической хартии.

В тоже время отдельные правовые формы иностранных инвестиций в ТЭК в российском правопорядке организованы, напротив, в рамках более благоприятных правовых режимов, чем те, которые применяются к национальным инвесторам в ТЭК. Действительно, например, такая форма иностранных инвестиций как соглашение о разделе продукции, введённая в российский правопорядок Федеральным законом от 30 декабря 1995 г. № 225-Ф3 «О соглашениях о разделе продукции»[11], создала для иностранного инвестора более благоприятную форму инвестиций в ТЭК, чем для национальных инвесторов. Так, например, данная 
форма инвестирования предполагает наличие права собственности иностранного инвестора на часть добытого энергоресурса, оставленного за ним после раздела продукции; льготное налогообложение; приоритетный порядок возмещения расходов на разведку и добычу полезных ископаемых; и, даже, возможность разрешения споров в международных (зарубежных) инстанциях[12]. Иначе говоря, правовое регулирование соглашений о разделе продукции свидетельствует, что иностранные инвесторы в ТЭК нередко поставлены в более выгодное положение, чем национальные. Такая, казалось бы, аномалия объясняется чаще всего не только необходимостью привлечения иностранных инвестиций, но и технологий, которыми нередко не обладают национальные компании сферы ТЭК. Как следствие, государства - в том числе и Россия -прибегают к данной форме иностранных инвестиций и, таким образом, де факто прибегают к применению в отношении иностранных инвесторов более благоприятного режима инвестиций, чем национальный режим.

В целом, в науке отмечается, что даже применение национального правового режима к иностранным инвесторам, ставит последних в более выгодное положение, чем национальных инвесторов. Так, Ануфриева А.А. пишет, что «...на практике предоставление национального режима ставит иностранных инвесторов в преимущественное положение. Во-первых, это происходит благодаря тому, что отстаивать свои интересы иностранцы могут не только в национальных судах, но и в независимых арбитражных учреждениях, а во-вторых, в связи с тем, что свои права они могут защищать не только на основе национальных законов, но и опираясь на международные стандарты обращения с инвесторами и права, предоставленные им в соответствии с международными договорами принимающего государства с государством-источником инвестиций»[13]. Таким образом, даже в отсутствии применения таких - более выгодных форм иностранного инвестирования в ТЭК как соглашение о разделе продукции - само применение национального режима к иностранным инвестициям нередко ставит их в более выгодное положение, чем национальных инвесторов.

Несмотря на особенности применения к иностранным инвесторам национального режима на практике они предпочитают применение либо международного права, либо одной из договорных форм инвестирования (например, концессионных соглашений или соглашений о разделе продукции).

Применение международного права к иностранным инвестициям в любом государстве является необходимым гарантом прав инвестора и, как следствие, привлекательности правового режима его инвестиций. Так, в частности отмечается, что «...охрана и защита иностранных инвестиций определяются правом государства, на территории которого осуществляются инвестиции, а не правом государства, из которого происходит инвестор. Результатом нестабильности этого права является отсутствие безопасности инвестора, поэтому, он ищет возможность обойти эти нормы права и воспользоваться защитой международного права. Именно по этой причине правоотношения в сфере инвестиций регулируются многочисленными конвенциями, количество которых продолжает увеличиваться»[14].

В свою очередь, применение договорного режима к иностранным инвестициям в ТЭК всегда рассматривалось инвесторами как наиболее привлекательное. Так, в частности, в науке уже отмечалось, что «...с точки зрения иностранных инвесторов, решение вопроса о стратегическом минеральном сырье на основе договора, вне всякого сомнения, предпочтительнее»[15]. Это связано с тем, что как в рамках договора концессии, так и в рамках соглашений о разделе продукции - наиболее часто используемых договорных формах иностранных инвестиций - применимое право разрабатывается самим контрактантами, что позволяет посредством диспозитивного метода правового регулирования определить применимое к отношениям право и не зависеть от вертикально применимых норм национального (чаще всего административного) права.

Иначе говоря, иностранные инвесторы ТЭК подходят с осторожностью к применению национального законодательства даже тогда, когда к ним применяется так называемый национальный режим, так как национальное право не всегда предоставляет им наиболее благоприятный режим правового регулирования инвестиций. Таким образом, они предпочитают либо применение международного права (чаще всего разработанного в рамках двусторонних договоров), либо применение договорных форм инвестирования с возможностью разрешения споров в международных (зарубежных) судебных инстанциях.

Таким образом, несмотря на однозначность правового режима иностранных инвестиций в ТЭК, который определяется общими положениями Федерального закона от 9 июля 1999 г. № 160-Ф3 «Об иностранных инвестициях в Российской Федерации» как национальный режим инвестиционной деятельности (ст. 4), он не является столь однозначным. Во-первых, ТЭК 
DOI: $10.7256 / 1811-9018.2016 .8 .19931$

При цитировании этой статьи сноска на doi обязательна

является особой сферой хозяйственных отношений, которая подпадает под исключения из национального режима, определенные ст. 4 федерального закона № 160, что в принципе позволяет законодателю применять к иностранному инвестору любой из возможных правовых режимов. В тоже время, государство, будучи заинтересованным в привлечении иностранных инвестиций в ТЭК все же применяет к ним наиболее благоприятный из возможных правовых режимов, т.е. национальный режим. Более того, на практике государства - в том числе и Россия - настолько заинтересованы как в иностранных инвестициях, так и технологиях разведки и добычи энергоносителей, что де-факто предоставляют иностранным инвесторам даже более благоприятный правовой режим, чем национальным инвесторам.

\section{Библиография:}

1. Собрание законодательства Российской Федерации, 1999, № 28, ст. 3493

2. Богатырев А.Г. Правовое регулирование инвестиционных отношений в Российской Федерации: Учебное пособие. - М., 1995. - 146 c.

3. Ануфриева А.А. Правовые режимы иностранных инвестиций в энергетику России: международно-правовые аспекты// Евразийский Юридический Журнал. 2011. №5 (36). - 16 с.

4. Договор к Энергетической Хартии и связанные с ним документы. - Секретариат Энергетической Хартии. - 2004. Брюссель. - 256 с.

5. Гудков, И.В. Договор к Энергетической хартии в контексте отношений Россия - ЕС //Энергетика и право. - М.: Юрист, 2008. - С. 495-528.

6. Российская газета от 7 мая 2008 г.

7. Вестник Высшего Арбитражного Суда Российской Федерации. 2001. № 3.- 6 с.

8. Собрание законодательства Российской Федерации, 1999, N 28, ст. 3493

9. Собрание законодательства Российской Федерации, 1999, № 28, ст. 3493

10. Лисицын-Светланов, А.Г. Энергетическое право: задачи дальнейшего развития отрасли //Правовое регулирование в сфере электроэнергетики и теплоснабжения. - М. : Юрист, 2013.- С. 70-71

11. Собрание законодательства Российской Федерации,1996. № 1. Ст. 18.

12. Байбекова Э.Ф. Соглашение о разделе продукции как гражданско-правовой договор в сфере инвестиционной деятельности. Дисс...канд. юрид. наук. Астрахань. 2015. С. 69-96.

13. Ануфриева А.А. Правовые режимы иностранных инвестиций в энергетику России: международно-правовые аспекты// Евразийский Юридический Журнал. 2011. №5 (36).- 203 с.

14. Селим Р.А. Правовые режимы иностранных инвестиций (вопросы теории)//Евразийский юридический журнал. 2009. - № 3 (10).- 54 c.

15. Курабнов Р.А. Правовое регулирование иностранных инвестиций в нефтяной и газовой промышленности. Дисс.... док. юрид. наук. - М.: - 2006. с. 166.

\section{References (transliterated):}

1. Bogatyrev A.G. Pravovoe regulirovanie investitsionnykh otnoshenii v Rossiiskoi Federatsii: Uchebnoe posobie. - M., 1995. $-146 \mathrm{~s}$.

2. Anufrieva A.A. Pravovye rezhimy inostrannykh investitsii v energetiku Rossii: mezhdunarodno-pravovye aspekty// Evraziiskii Yuridicheskii Zhurnal. 2011. №5 (36). - 16 s.

3. Gudkov, I.V. Dogovor k Energeticheskoi khartii v kontekste otnoshenii Rossiya - ES //Energetika i pravo. - M.: - Yurist, 2008. - S. 495-528.

4. Lisitsyn-Svetlanov, A.G. Energeticheskoe pravo: zadachi dal'neishego razvitiya otrasli //Pravovoe regulirovanie v sfere elektroenergetiki i teplosnabzheniya. - M. : Yurist, 2013.- S. 70-71

5. Baibekova E.F. Soglashenie o razdele produktsii kak grazhdansko-pravovoi dogovor v sfere investitsionnoi deyatel'nosti. Diss...kand. yurid. nauk. Astrakhan'. 2015. S. 69-96.

6. Anufrieva A.A. Pravovye rezhimy inostrannykh investitsii v energetiku Rossii: mezhdunarodno-pravovye aspekty// Evraziiskii Yuridicheskii Zhurnal. 2011. №5 (36).- 203 s.

7. Selim R.A. Pravovye rezhimy inostrannykh investitsii (voprosy teorii)//Evraziiskii yuridicheskii zhurnal. - 2009. - № 3 (10). $-54 \mathrm{~s}$.

8. Kurabnov R.A. Pravovoe regulirovanie inostrannykh investitsii v neftyanoi i gazovoi promyshlennosti. Diss....dok. yurid. nauk. - M.: - 2006. s. 166. 